\title{
Objectivity and Representative Practices across Artistic and Scientific Visualisation
}

\author{
Chiara Ambrosio \\ Department of Science and Technology Studies \\ University College London \\ c.ambrosio@ucl.ac.uk
}

\section{Visualisation, Representation, and the Question of Objectivity}

Lorraine Daston and Peter Galison's (2007) work on scientific atlases has opened new lines of inquiry into the relations between objectivity and visual practices in science. Implicit in their narrative, and in need of further investigation, are some suggestions on how historical reflections on visual practices in science incorporate its evolving relation with the visual arts. In this chapter I chart the story of how artists participated in the practices of observation that Daston and Galison (2007:19ff) compellingly define as "collective empiricism". In doing this, I use their narrative as a point of departure to narrate a story that is deeply intertwined with that of scientific objectivity, and which has remained so far pretty much untold. My aim is to show that the history of scientific objectivity has constantly crossed paths with the history of artistic visualisation, from which it has received some powerful challenges. Drawing on three case-studies from the eighteenth, nineteenth and twenty-first centuries, I argue that, by challenging the current canons of correct and accurate forms of visualisation and representation, artists played a crucial role in shaping the history of objectivity - mainly by vocalizing their objections to it.

My concern in this chapter is twofold, and it ultimately aims to reconcile historical and epistemological accounts of visual practices in science and in the visual arts. At a basic level, my aim is to add new interpretative layers to images that are too often taken for granted and classified strictly as "scientific" or "artistic". Looking at the history of how certain artistic and scientific representations came to be the way they are reveals that scientific visualisation is imbued with aesthetic commitments, and that artistic visualisation constantly capitalizes on - and responds to - scientific and technological innovation. But in charting this history, my concern is primarily an epistemological one. Complicating the story of what count as accurate representations 
offers a challenge to current accounts of representation in philosophy of science.

These accounts far too often qualify it as a relation between representing and represented facts which needs to be spelled out analytically. ${ }^{1}$ While making sense of what constitutes representation is a central epistemological problem that deserves philosophical investigation, my claim is that representation, construed as an epistemological relation, should be explained in a historical fashion. The question is perhaps still one of discovery versus justification: current philosophical accounts still concentrate on a normative quest for the formal constituents of representative relations, without paying much attention to the processes that led to their construction. What I want to stress, instead, is that representation is a relation which is discovered through processes and practices that are historically grounded, and that in many cases incorporate conversations and controversies between artistic and scientific ways of seeing.

Historicising the category of representation has also the advantage of reinforcing its vital connection with visualization - a connection that is rarely addressed in current philosophical discussions. The atlas images discussed by Daston and Galison are a case in point, as they offer a glimpse of how collective practices of observation and shared styles of visualization become essential to "discern and stabilise" (Daston 2008:98) the objects of scientific investigation that appear on the atlas pages. In the course of this chapter, I add a new dimension to Daston and Galison's narrative, by showing that scientists were not alone in this process, and that in many cases they did not have the final word on what counts as an accurate representation. The story that I present is one about the contingencies that underpin what we usually regard as ready-made images, and the controversies that arise when artists and scientists respond to each other's modes of visualisation. ${ }^{2}$

Throughout this chapter, I advocate a complementary view of visualisation and representation, which I consider first and foremost as historically grounded practices and as constitutive components of experimentation and inquiry in science and in the visual arts. I conclude with a discussion of what a historicised view of representation has to offer to epistemology and the philosophy of science. My final suggestion is to shift the focus of philosophical inquiry from a concept of

\footnotetext{
${ }^{1}$ An overview of the current debate on the nature of scientific representations is in Suárez (2010).
} 
"representation" to a historically grounded and pragmatic view of "representative practices", which better accounts for the key boundary areas in which art and science have complemented each other, and will continue to do so in the age of computerisation.

\section{Visualizing and representing in the Eighteenth Century: "Truth-to- Nature"}

"And as skeletons differ from one another, not only as to the age, sex, stature and perfection of the bones, but likewise in the marks of strength, beauty and make of the whole; I made choice of one that might discover signs of both strength and agility; the whole of it elegant, and at the same time not too delicate; so as neither to shew a juvenile or feminine roundness and slenderness, nor on the contrary an unpolished roughness or clumsiness; in short, all of he parts of it beautiful and pleasing to the eye. For as I wanted to shew an example of nature, I chused to take it from the best pattern in nature".(Albinus [1747] 1749, sig. b.r.)

It is with these remarks that Bernhard Siegfried Albinus, professor of anatomy and surgery at the University of Leiden, introduced the illustrations that accompanied his impressive Tabulae Sceleti et Musculorum Corporis Humani, published in 1747.

What Albinus was after, as a scientist, was an accurate representation of the human body, one which could take him beyond nature's variety and individual imperfections, and condense his philosophical ideal of "homo perfectus" (Punt, 1983; Hildebrand, 2005:557). Albinus' perfect man required the choice of "the best pattern in nature". His ideal skeletons could not be too short, too tall or excessively slender, nor should they display the overly muscular appearance which was characteristic of the Baroque bodies featured in Andeas Vesalius' De Humani Corporis Fabrica two centuries earlier. $^{3}$

Albinus' quest for an idealised image, which might or might not have had a concrete counterpart in nature, is only one of the examples that Daston and Galison (2007: 70ff) discuss as part of what they define as "truth-to-nature". This was the representative standard that eighteenth century savants pursued before the term "objectivity" became the hallmark of accurate representations: "[Eighteenth century]

\footnotetext{
${ }^{2}$ Here I implicitly draw on the rich STS literature on scientific controversy, which includes Latour (1987), Collins and Pinch (1993), and more recently Castel and Sismondo (2008).

${ }^{3}$ Even more importantly, Albinus' "homo perfectus" was a man, and as such his skeleton should definitely not display any roundness or frailty that was typically female. Women entered anatomical classification only toward the end of the Eighteenth century, with Samuel Thomas von Soemmering claiming to have published the first illustration of a female skeleton. Schiebinger (1986) gives an account of the political and ideological implications of Soemmering's highly idealised female skeleton.
} 
images were made to serve the ideal of truth - and often beauty along with truth - not that of objectivity, which did not yet exist" (Daston and Galison, 2007:104). Truth-tonature imposed thorough familiarity with nature's variations, which served the purpose of "perfecting" individual occurrences as encountered in nature. Eighteenth century sages had the scientific duty to correct nature for the sake of truth: their illustrations show that for them representing was continuous with the act of discernment required to visualise phenomena not in their singularity, but in their most general, ideal manifestations.

Very few scientists could achieve the ideal of truth-to-nature by themselves. For this purpose, eighteenth century scientists needed the collaboration with artists $-\mathrm{a}$ collaboration that ultimately aimed at a fusion of the head of the scientist with the hand of the artist (Daston and Galison, 2007:88). But the story of artists and scientists working side by side, which Daston and Galison aptly describe as "four-eyed sight" (ibid.), is also one of conflict and controversies, of scientists enforcing ideas of perfection and truth and artists reacting, in more or less overt and often quite inventive ways. While Daston and Galison pay some attention to this collaborative dimension, I suggest that much more can be learned from what remains hidden in the background of images that are usually perceived as sanctioning the victory of scientific accuracy (however construed) over artistic interpretation. It is here that the case of Albinus' collaborator, the Dutch artist and engraver Jan Wandelaar, offers an insightful example of the ways in which artists engaged with, and challenged, scientific modes of observation and visualisation - with rather spectacular results.

Wandelaar's name is often mentioned by specialists as the hand behind Albinus' Tabulae. ${ }^{4}$ Strangely enough, however, historians have paid scant attention to the accomplishments of Albinus' collaborator. Details of Wandelaar's artistic activity remain at present scattered throughout the literature, which mostly focuses on Albinus' innovations in the field of anatomy. Piecing together this fragmented information reveals that Wandelaar cultivated a range of scientific and intellectual interests which converged into his illustrations. In particular, Wandelaar's artistic practice was strongly driven by his knowledge of natural history, which he cultivated in parallel with his work as an illustrator and engraver of anatomical atlases. It was

\footnotetext{
${ }^{4}$ See for example Choulant (1962), Ferguson (1989), Elkins (1986) and Huisman (1992).
} 
this knowledge that ultimately allowed him to give Albinus' Tabulae their distinctive character.

Following the death of his son, Wandelaar moved into Albinus' house and lived there for about twenty years. The two had met in 1723, when they were both working on a re-edition of Vesalius' De Humanis Corporis Fabrica (Huisman, 1992:2, Hildebrand, 2005:559). By the start of his work on the plates of Albinus' Tabulae, Wandelaar was already an accomplished illustrator and engraver. He had been collaborating with scientists at least since the 1720s, having designed and executed among other things - the frontispiece of Linneus' Hortus Cliffordianus, published in 1737 (Daston and Galison, 2007:57). Under Albinus' strict guidance, Wandelaar perfected his scientific training, and his efforts to accommodate the scientist's requirements of accuracy and precision paid back. Albinus himself, in his memoirs, praised the artist's skills, his inquisitive mind and his willingness to learn human anatomy: "I have always wondered at his spirit, his patience and his resolution; he is moreover ardent and never without a certain impetuous eagerness of effort" (Huisman, 1992:2). ${ }^{5}$

With Wandelaar, Albinus had found a convenient way to avoid one of the major sources of inaccuracy that had affected anatomical representations until his time: the inevitable mismatch between anatomical visualisation and its concrete representation in the final engraved image. The passage from anatomical preparations to drawings, and from these to copperplates or woodblocks, required the intervention of an engraver to transfer the artist's drawings on plates. But while the artist's eye and hand had been trained directly by the anatomist, the engraver only entered this process in its final stages - and this was the cause of most mistakes. Wandelaar could offer both services - drawing and engraving - thus securing the necessary continuity in the process of producing anatomical representations under the close supervision of Albinus himself.

Despite this, Albinus still demanded full control over his collaborator's work, imposing observational skills and methods to ensure that Wandelaar would learn the most accurate way of visualising and perfecting anatomical features. The strictest control of the scientist over the artist was indispensable, in order to avoid the lack of accuracy that Albinus thought affected earlier anatomy atlases (to which the Tabulae

\footnotetext{
${ }^{5}$ Huisman reports this quotation from the preface to Book 1 of Albinus' Academicarum Annotationum.
} 
were supposed to offer a direct corrective), such as Vesalius' Fabrica or Govard Bidloo's 1685 Anatomia Humani Corporis (Huisman 1992:2).

A major concern for Albinus was the effect of distortion deriving from drawing in perspective. The problem was due to foreshortening, and to the fact that the artist could observe only part of its subject at a right angle. Thus, whatever happened to be at the centre of the artist's field of vision, and viewed frontally, was depicted correctly. But the parts that were further removed from the centre were observed - and consequently represented - at progressively sharper angles, with inevitable distortions and inaccuracies.

In an attempt to preserve both anatomical detail and correct representations, Albinus devised a two-steps method that constituted a genuine innovation in the practice of anatomical illustration. This involved a system of double grids, or "diopters", which would allow the artist to maintain the proportions of the "homo perfectus", along with preserving the most accurate degree of detail at the right angle of observation (Huisman, 1996:3). ${ }^{6}$

The first step consisted in drawing the body or skeleton from a distance. The subject to be depicted was placed at 40 Rhenish feet (approximately 12,5 metres) from the artist. A first, large diopter, composed of a grid of squares measuring 7,3 $\mathrm{x}$ 7,3 centimetres, was placed in front of the body. The artist drew on a sheet divided in the same manner as the diopter, at this stage only focusing on a general layout of the body, without introducing any detail (Huisman, 1996:4).

The second step consisted in filling in the initial life-size outline with anatomical details depicted with the utmost accuracy and precision, at the same time avoiding perspectival distortions. For this purpose, Albinus devised a smaller diopter, with a grid whose squares were one tenth of the size of the large diopter. Both diopters were placed in front of the body, with the smaller grid at a distance of 4 Rhenish feet from it. The smaller diopter had to correspond precisely with the squares forming the grid of the larger one, so that each 7,3 x 7,3 centimetres square on the larger grid would be divided in a hundred squares ten times as small. This system

\footnotetext{
${ }^{6}$ The double grids system had been devised for Albinus by Willem 'sGravesande, whose Essai de Perspective had been published in 1711 (Elkins, 1986:94).
} 
allowed Wandelaar to reproduce the details as if they were observed at 40 Rhenish feet without distortions (Punt, 1983:21-32). ${ }^{7}$

Historians have paid considerable attention to Albinus' method - and rightly so, as his experiments in measurement and accurate representation were the first of their kind in the eighteenth century. There is, however, an aspect of the Tabulae that has remained relatively neglected in the literature, and that constitutes their most striking feature: the backgrounds of the engravings. Albinus' idealised bodies are placed in floral, idyllic landscapes, and surrounded by neo-classical architectural elements. The images and symbols of vitality presented in the backgrounds were in part related to Albinus' ideas about the unity of nature (Hildebrand, 2005:561); however, they also constituted Wandelaar's hard-gained space for artistic expression. ${ }^{8}$ It was in fact Wandelaar who had convinced Albinus about the importance of the backgrounds of the plates, which he justified as an effort "to preserve the proper light of the picture, for if the space around the figure and between its parts were white, the light would suffer". 9 Alas, Wandelaar's effort to preserve "the proper light of the picture" resulted in the two illustrations that were to become the symbol of Albinus' atlas: tables IV and VIII (fig. 1 and 2), in which the ideal skeleton is depicted with an equally well proportioned rhinoceros in the background.

\section{[figures 1 and 2 here, both $1 / 2$ page]}

Fig. 1. Bernard Siegfried Albinus, Tabulae Sceleti et Musculorum Corporis Humani, Plate IV. Courtesy of the Wellcome Library, London.

Fig. 2. Bernard Siegfried Albinus, Tabulae Sceleti et Musculorum Corporis Humani, Plate VIII. Courtesy of the Wellcome Library, London.

\footnotetext{
${ }^{7}$ Historians diverge on how exactly Albinus used the second grid. Huisman (1994:6ff) recalculates the size of the second diopter and adds that the life-size drawing thus obtained was further scaled to folio size by transferring the grid of 7,3 x 7,3 centimetres square to one with a further grid of 2,5x 2,5 centimetres.

${ }^{8}$ Wandelaar eventually gained complete freedom as to what to include in the backgrounds. For instance, in the Tabula Musculorum II, a muscle-man is presented in front of a stairway with a sculpted lion in the background. I am grateful to Andrea Fredericksen, curator of the UCL Art Museum, for bringing this engraving to my attention. The table, from the 1749 English translation of Albinus' Tabulae, is part of the UCL Art Collections.

${ }^{9}$ Quoted in Elkins (1986:94) and Ferguson (1989:232). Both report Albinus' quote (originally in the Academicarum Annotationum) from earlier editions of Choulant (1962).
} 
The animal in question is Clara, a female Indian rhinoceros that arrived in Leiden in 1741 and travelled through Europe between 1746 and 1756 (Clarke 1974:116; Rookmaaker, 2005:239). Clara is also known as the "Leiden rhinoceros", a name she was given after her Dutch owner, Captain Douvemont van der Meer of Leiden (Clarke, ibid.). Historians usually explain the presence of Clara in the background of Albinus' illustrations as an exotic rarity which added an element of sophistication to the Tabulae (Hildebrand, 2005:561; Daston and Galison, 2007:72). This is partly true (Albinus himself substantiated this explanation in the text accompanying the plates), but there is more to this story.

What historians often neglect is that, by the publication of Albinus' Tabulae in 1747, Wandelaar had been drawing images of the rhinoceros for at least twenty years. In 1727 he was commissioned to illustrate the Dutch translation of the complete description of the geography, ethnography and natural history of Cape of Good Hope written by the German naturalist Peter Kolb. The work, originally published in German in 1719, devoted almost two folio pages to a description of a two-horned African black rhinoceros. Interestingly, the plates of the German edition conflicted with Kolb's description, in that they portrayed the rhinoceros according to a tradition dating back to Dürer's 1515 iconic representation of the animal. Following Dürer, most of these traditional illustrations, mainly based on second-hand accounts of the rhinoceros' features, presented the animal as one-horned (which is characteristic of the Indian species), covered by a thick armour and with a smaller spurious horn on the shoulders (Rookmaker, 2005:365ff).

Wandelaar's commission required him only to copy the plates from the 1719 edition of Kolb's book, but in fact he produced two different representations, both eventually included in the final publication: a traditional, Dürer-like depiction of the rhinoceros, which matched the illustration included in the German edition, and a second image, which corrected and rectified it by following meticulously Kolb's description (Rookmaaker, 1976:88). ${ }^{10}$ In this second illustration, Wandelaar's black rhinoceros is represented, probably for the first time, with a smooth skin and two

\footnotetext{
${ }^{10}$ Wandelaar's depiction of the rhinoceros here crosses paths with the taxonomical concerns surrounding the classification of the animal and its representation in the Eighteenth century. Only in 1758 Linneus provided the name Diceros bicornis for the two-horned African rhinoceros in his Systema Naturae, and even then the animal remained pretty much unknown in Europe. Most depictions continued to be based on specimens of one-horned Indian Rhinoceros Unicornis, which were best known in Europe. See Rookmaaker (2005) and Hanson (2010).
} 
horns. With this bold move, Wandelaar became one of the first artists who broke with the established tradition that had dominated the iconography of the rhinoceros - and even affected its classification - for over two hundred years. ${ }^{11}$

The story of Wandelaar's fascination with the rhinoceros and his role in the development of its iconography renders the presence of the animal in Albinus' Tabulae much less surprising. Far from being merely a fanciful and sophisticated addition to Albinus' anatomical works, the background of plates IV and VIII tells a story which runs in parallel to the one presented in the foreground of the engravings a story about the insightful ways in which artists occasionally interfered with the criteria for accurate representation imposed by scientists to pursue their own agendas, in ways that eventually became even scientifically acceptable.

The inclusion of the rhinoceros in Albinus' plates must have involved a great deal of negotiation. The fact that Clara belonged to the one-horned, Indian species of rhinoceros helped Wandelaar's cause, as her features were far more compatible with traditional representations of the animal than the two-horned African species he drew in 1727 (here one cannot avoid wondering whether Albinus would have dismissed a two-horned rhinoceros as one of nature's many exceptions!).

Hints of the reasons that Wandelaar might have used to persuade Albinus can be inferred from the commentary to the tables, where Albinus himself explicitly justifies the presence of the rhinoceros in the background of the plates as follows:

"We conclude this table, and the eight, by exhibiting in the back ground the figure of a female Rhinoceros that was shewed to us in the beginning of the year 1742, being two years and a half old, as the keepers reported. We thought the rarity of the beast would render these figures of it more agreeable than any other ornament resulting from mere fancy. The figures are just, and of a magnitude proportionable to the human figure contained in these two tables". (Albinus [1747] 1749, sig.g.1.v.)

Here Albinus' concern is maintaining the proportions: the presence of the rhinoceros in the plates is somehow justified by the fact that her depiction is "just" and "proportionable" to the human skeleton. At the same time, however, Albinus confesses between the lines that the plates partly betray his ideal of truth-to-nature. What one sees in the background is a particular rhinoceros, observed alive in 1742,

\footnotetext{
${ }^{11}$ In the years following Kolb's publication, Wandelaar found more opportunities to cultivate his fascination for the rhinoceros. Two pages of sketches illustrating the details of a preserved specimen
} 
when she was two and a half years old: Clara appears to be the only identifiable character in Albinus' Tabulae! With a brilliant operation of visual persuasion, Wandelaar managed to sidestep Albinus' quest for idealised types, and brought the particular right at the core of the two most representative illustrations of his anatomical atlas. Clara's cumbersome presence in the background of the plates vindicates the role of Wandelaar, and with him the crucial contribution of artists, in shaping and challenging what counted as an accurate representation in the eighteenth century.

Daston and Galison's view that eighteenth century "four-eyed sight" required the subordination of artists to scientists thus needs to be read with a few caveats. Some artists, like Wandelaar, approached accurate representation with all the dilemmas arising from the conflict between the needs of artistic experimentation and the impositions deriving from the canons of scientific accuracy. Hence, while the idealised bodies in the foreground of Albinus' illustrations are a sign of the ethos of discipline (well epitomised by the double grids and calculations) enforced by the scientist upon the artist, the rhinoceros in the background of plates IV and VIII shows that in some cases artists opposed their resistance against the visual restrictions imposed by the pursuit of truth-to-nature. Ultimately, the story of Wandelaar's rhinoceros shows that eighteenth century artists did not necessarily sacrifice their commitments for the greater cause of scientific accuracy: instead, they approached scientific illustrations with their own visual priorities, leaving more or less visible traces of their presence in the pictures.

The tensions, conflicts and stratagems of persuasion that characterise the relationship between artists and scientists add a new dimension to Daston and Galison's narrative, and they are not restricted merely to the eighteenth century. In the mid-nineteenth century a new representational mode, that of mechanically reproduced images, saw artists and scientists openly arguing over the status of accurate representations. This controversy was openly construed under the heading of "objectivity", a term which entered the artist's vocabulary when photography made its first appearance in artistic practice. 


\section{Mechanical Objectivity: a View from Artistic Practice}

Since 1839, when the first daguerreotype was presented at the Paris Académie des Sciences, the status of photography had been the subject of animated discussions. Scientists initially regarded it as the ultimate tool to obtain accuracy in observation and measurement. Its mechanical, reproducible and reliable nature was a reason to believe that it would function as "an artificial retina... at the disposal of the physicists", as Jean Baptiste Biot enthusiastically announced to the assembled members of the Académie des Sciences (quoted in Wilder, 2009:9). By the end of the $19^{\text {th }}$ century, photography was used by scientists as an instrument of observation of phenomena which were considered otherwise unobservable, and it was employed as a form of measurement and as a means of obtaining experimental evidence (DidiHubermann, 1986; Daston and Galison, 2007; Wilder, 2009).

Daston and Galison place the emergence of the modern concept of objectivity almost concomitantly with the birth of photography. Despite the fact that their concept of mechanical objectivity extends to a much broader range of recording instruments, photography constitutes a keystone in the process that led scientists to adopt an attitude of noninterventionism toward the objects of their inquiries:

\footnotetext{
"One type of mechanical image, the photograph, became the emblem for all aspects of noninterventionist objectivity...This was not because the photograph was more obviously faithful to nature than handmade images many paintings bore a closer resemblance to their subject matter than early photographs, if only because they used color - but because the camera apparently eliminated human agency. (Daston and Galison, 2007: 187).
}

Mechanical reproducibility contrasted sharply with the eighteenth century ideal of truth-to-nature. Eighteenth century representations required the willful intervention of the scientist - indeed, willful intervention was just what gave images their credibility and scientific status. Mechanical objectivity, on the other hand, required an attitude of asceticism (in its strongest moral connotations) toward the objects of scientific inquiry (Daston and Galison, 2007:120ff). Letting nature speak for itself became the nineteenth century scientist's motto, human intervention being now replaced by a procedural use of image technologies which would ensure the elimination of the scientist's judgment from image-making, and even from the process of visualizing. This form of objectivity went hand in hand with the increased scientific 
reliance on recording instruments, which, like the camera, seemed to promise the possibility of removing human agency altogether.

Contrary to scientists, artists sought in photography a creative medium that could enhance willful intervention. The earliest stages of artistic photography saw artists treating the expressive possibilities offered by the camera as complementary and comparable to painting. Pictorialism, a movement that became dominant in the 1890s, explicitly aimed to differentiate artistic photography from scientific photography by treating the former as painting. Pictorialist photographers accomplished this by selecting carefully the content and the perspective from which photographs were taken, and intervened on the pictures by directly retouching them. This practice aimed to bring the artist's subjective intervention right at the core of technical photography - indeed, it aimed to stress the impossibility of removing agency from photography, no matter what scientists thought or how they used their photographic machinery.

Pictorialists' attacks against the supposedly objective nature of scientific photographs were open and frequent. Mechanical objectivity saw artists overtly reacting to science, in a manner that sharply contrasts with Wandelaar's somehow respectful intrusion in the background of Albinus' drawings. Open controversy often took sarcastic tones, as in a 1903 article aptly entitled "Ye Fakes", in which the pictorialist photographer Edouard Steichen explicitly mocked the attitude of asceticism preached by the supporters of noninterventionist objectivity:

"Some day there may be invented a machine that needs but to be wound up
and sent roaming o'er the hill and dale, through fields and meadows, by
babbling brooks and shady woods - in short, a machine that will
discriminatingly select its subject and by means of a skillful arrangement of
springs and screws, compose its motif, expose the plate, develop, print, and
even mount and frame the result of its excursion, so that there will remain
nothing for us to do but send it to the Royal Photographic Society's
exhibition and gratefully to receive the Royal Medal". (Steichen, 1903:107).

Steichen's article first appeared in a journal whose mission was to advance artistic photography, granting its status as a form of art in its own right. The journal's name was Camera Works, and its founder, Alfred Stieglitz, occupies a central place in modernist responses to mechanical objectivity. Contrary to his contemporaries, Stieglitz did not reject objectivity altogether. By proposing an experimentalist aesthetics based on a view of the artist as a trained observer, Stieglitz challenged both 
the resistance to mechanical reproducibility pursued by pictorialist photographers and the noninterventionist attitude cultivated by scientists in the mid-nineteenth century.

Stieglitz is widely recognized as the pioneer of modernist photography and the key impresario of American avant-garde. A visionary intellectual and promoter of European modernist movements in America, he played a key role in defining the theoretical and practical foundations of photography as a form of art. What art historians often neglect, however, is that the foundations of his practice as a photographer lay in the climate of experimentalism that characterized German science in the 1880 s. $^{12}$

Born in Hoboken (New Jersey) from a German family, Stieglitz moved to Berlin in 1881 to enter the Charlottenburg Polytechnic and begin a degree in mechanical engineering. Stieglitz's biographers have often dismissed his student years as an initial obstacle to the development of his artistic career (Lowe 2002:74). Yet, the impact that his engineering and chemical training had on his subsequent artistic production tells a different story.

In the 1880 s Berlin hosted a lively scientific community, which attracted the young Stieglitz since his early days at the Polytechnic. In parallel with his initial steps in the field of photography, he attended lectures by prominent figures such as the physicists Hermann von Helmholtz and Heinrich Hertz, the physiologist Emil DuBois- Reymond and the anthropologist and pathologist Rudolf Virchow (Kiefer, 1991:61ff ; Lowe, 2002: 73). But the two figures who influenced Stieglitz in the most dramatic way, eventually compelling him to switch from engineering to chemistry, were the chemists August Hofmann and Hermann Vogel.

Hofmann is especially known for his work on coal tar and his contribution to the development of aniline dyes, which laid the foundations of the German dye industry. A student of Justus Liebig at the University of Giessen, he had been, under his teacher's guidance, a pioneer in the transition from analytic to synthetic organic chemistry. Hofmann adopted and extended Liebig's successful methodology, whose distinctive trait was the integration of teaching and research in the practical setting of the chemical laboratory. ${ }^{13}$ Since his early years under Liebig's guidance, Hofmann had structured his laboratory as a research community, in which chemical knowledge

\footnotetext{
${ }^{12}$ The only exception to these accounts is Kiefer (1991).
} 
was conveyed through practice. Most of the daily learning happened by observing and doing, whereas lectures provided a theoretical background for students who lacked prior chemical training. Indeed, one of the most important methodological points that Hofmann adopted from Liebig was a systematic philosophy of chemical practice, whereby "experimental skill as well as theoretical convictions guided the analyst along a highly uncertain path from experiment to formula" (Jackson, 2009:16).

The concept that practice, far from being subordinate to theory, was constitutive of it became especially important to Stieglitz. The scientific aesthetics underpinning his practice as a photographer revolved around the idea that photography and science shared the same experimental basis and that in both cases theoretical considerations emerged as generalizations from practical experience. When, in 1905, Stieglitz established the Little Gallery at 291-293 Fifth Avenue, in New York, he characterized it as his "experimental station", an expression that was adopted by his closest collaborators:

"It should be remembered that the Little Gallery is nothing more than a laboratory, an experimental station, and must not be looked upon as an Art Gallery in the ordinary sense of the term" (De Zayas, 1910:47).

Stieglitz's breakthrough as the pioneer of modernist photography and as the impresario of avant-garde art in America consisted in adopting (and adapting) a Liebig-inspired model of laboratory conceived as a social space with its community, collective observational practices, shared representational conventions and tacit ways of conveying knowledge through action. Moreover, just as a scientific research community, Stieglitz and his laboratory group disseminated their findings through the journal Camera Work (published between 1903 and 1917), which became one of the most important instruments for the promotion of avant-garde in the $20^{\text {th }}$ century (Eversole, 2005).

Stieglitz's chemical training under Hofmann prevented him from unconditionally adopting the attitude of extreme interventionism that characterised pictorialist approaches to photography. While pictorialism still maintained a prominent place in Camera Work throughout the years of its publication, Stieglitz departed from it to embrace a more complex aesthetic position, which he identified as

\footnotetext{
${ }^{13}$ On Liebig's laboratory see Holmes, 1989 and Jackson, 2009. On Hofmann's adoption of Liebig's model see Bentley, 1970; Bentley 1972; and Meinel 1992.
} 
"straight photography". This new mode of visualization hinged on the role of trained observation, which Stieglitz considered as the main route to achieve objectivity through experimental inquiry. Stieglitz's concept of the "seer" behind the camera explicitly appeals to a scientific view of trained eye, whose active judgment selects and interprets relevant aspects of a complex reality, and transposes them in a "true" photograph:

"It is high time that the stupidity and sham in pictorial photography be struck a solar plexus blow... Claims of art won't do. Let the photographer make a perfect photograph. And if he happens to be a lover of perfection and a seer, the resulting photograph will be straight and beautiful - a true photograph. (Stieglitz, 1910, in Adato, 2001)

In this respect, I argue that Stieglitz's approach to photography anticipates the transition from the asceticism of mechanical objectivity to the community-informed ethos of inquiry that Daston and Galison (2007:309ff) characterize as "trained judgment". Distinctive of twentieth-century image-making, trained judgment was a reaction to the constraints imposed by mechanical reproducibility. This new representational mode incorporated scientists' progressive awareness that judgmentinflected vision, rather than the "blind sight" of mechanical objectivity, was the goal of scientific visualization. Such an ethos of inquiry, which built interpretation in the process of image-making without depriving photographs of their "straight" character, was just what Stieglitz had cultivated within the experimental setting of his galleries.

One way of assessing this claim is through a work that constitutes a turning point in Stieglitz's aesthetics: his 1907 photograph The Steerage (fig. 3). The image condenses the artistic outcomes of his evolving views on scientific experimentalism and marks the culminating point of his synthesis of art and science.

\section{[Fig. 3 here]}

Fig. 3. Alfred Stieglitz, The Steerage, 1907. From Camera Work, no. 36 (October 1911), p. 37. Copyright: DACS. Courtesy of the Bridgeman Art Library.

The story of The Steerage is well known to art historians. ${ }^{14}$ Stieglitz was traveling to Europe on board the liner SS Wilhelm II. Despite having a place on the

\footnotetext{
${ }^{14}$ For a recent account of Stieglitz's 1907 photograph see Francisco and McCauley (2012).
} 
first class deck, he wondered with his camera in the vicinities of the steerage, with the purpose of taking pictures. In his memoirs, he recalls the taking of The Steerage as follows:

"A round straw hat, the funnel leaning left, the stairway leaning right, the white drawbridge with its railings made of circular chains - white suspenders crossing on the back of a man in the steerage below, round shapes of iron machinery, a mast cutting into the sky, making a triangular shape. I stood spellbound for a while, looking and looking and looking. Could I photograph what I felt, looking, looking and still looking? I saw shapes related to each other. I saw a picture of shapes and underlying that the feeling I had about life". (Stieglitz, in Norman (ed.) 1942-43: 128)

The Steerage is usually regarded by art historians as a photograph whose implications are mainly political and social. Without refuting this interpretation, I would like to suggest that there is more to Stieglitz's photograph. My claim is that the visual effectiveness of The Steerage lies primarily in its conceptual nature - what Stieglitz compellingly defines as seeing "shapes related to each other". Conceptual relations are what Stieglitz was after in light of his scientific training. By concentrating on the inner relations between forms, in The Steerage Stieglitz obtained a photographic representation that verged on the conceptual. Far from exhibiting a faithful, point-to point correspondence to a concrete event, The Steerage condenses Stieglitz's awareness that photography, as any form of representation, entails a process of abstraction and generalization from visual experience. His artistic quest for structure and form, for visualizing general properties beyond what was mechanically reproducible on the photographic plate, found its ultimate realization in The Steerage, and was modeled on his chemical laboratory practice.

Under Hofmann's guidance, Stieglitz had come to appreciate that chemical knowledge proceeds from experiment to general formulae. As results of practical experimentation, chemical formulae are abstractions of the objects they stand for. At the same time, however, they are richer and more informative than their objects, for they capture structural properties of the experimental processes from which they arise. Moreover, by practicing chemistry in Hofmann's laboratory, Stieglitz had become familiar with the view that practice and process are constitutive components of theoretical knowledge. These basic principles allowed him to approach photography as a scientific problem to be solved experimentally, and devise a novel approach to photography which ultimately dispensed with exact correspondence as a criterion for representation. 
With The Steerage, Stieglitz found a satisfactory balance between his photographic practice and his experimental philosophy. By challenging both naïve photographic realism and the simplistic appeal to subjectivity pursued by pictorialist photographers, he formulated a novel relation at the basis of his photographic representations, one which was built on the trained observer's active judgment in visualizing and selecting salient properties from the objects of photographic inquiry.

Stieglitz was well aware that photography, as every act of observation, is theory-dependent. And the theory that informs photography is in turn shaped by the needs and goals of the photographer, along with his tools, chemical equipment and laboratory practice. His scientific training provided him with a renewed awareness of this aspect of photography and of the experimental process that guides the photographer from "looking, looking and still looking" to the final image - a "true" photograph. This characterization of Stieglitz's approach to photography suggests that his formulation of objectivity was not at all concerned with mechanical reproducibility. Far from preaching restraint and asceticism, Stieglitz recognised that objectivity required a trained "seer", and that the informed activity of trained observers constituted the crucial connection between artistic visualisation and mechanically reproduced images.

Historians and philosophers of science far too often tend to confine the changes that affected scientists' views about objectivity - especially with respect to mechanical reproducibility - only within science. But then there was art. There were pictorialist photographers who reacted to photographic objectivity with the compelling means of artistic experimentation and singled themselves out because of their obstinacy with the subjective aspects of artistic practice against the attitude of non-interventionism preached by scientists. And there were scientifically-minded artists, such as Stieglitz, who sought for a compromise between resistance and restraint. In this process, scientific visualization was a parameter that artists had constantly in mind: whether they adopted it or reacted to it, science informed their visual inquiries into the ways in which representations capture perspicuously some aspect of the world.

\section{Artistic Visualization as "Critique"}


Daston and Galison's narrative stops at a point that marks a crucial junction in the history of visualization: the contemporary shift from "representation" to "presentation" (Daston and Galison, 2007:382ff). In the age of computerisation, visualisation challenges the boundaries between the artifactual and the natural: the new scientific images fulfil the purpose of manipulating the real - and they do so in an aesthetically pleasing way. This new representational mode opens a new chapter in the story of the relations between artistic and scientific visual practices: far from being disciplined and restrained, artists are now invited to take a central place in the scientific enterprise, as privileged instruments of scientific visualisation. This suggests that the time of controversy, of artists having to hide themselves in the background of anatomical engravings or having to engage in arguments against the reliability of mechanically reproduced images, is finally over.

Such an optimistic view needs to be taken with a pinch of salt. Several contemporary collaborations between artists and scientists still tend to relegate the role of artists as mere accessories in the toolkit of scientific visualisation - a passive role that requires their vision to be disciplined in some way. A parallel (and equally perplexing) assumption is that the artist's work is a mere means to add a visually pleasant dimension to scientific visualisation, which would magically render science more communicable.

What I would like to present in this section is an alternative view, which stresses one final time the critical role of the artist in challenging what scientists take as granted, objective and unquestionable. My view is rooted in history: the casestudies I have presented so far show that looking at the controversies that divided artists and scientists over what counts as accurate representation contributes to add an entirely new layer to the story of objectivity. At the same time, a normative lesson can be drawn from this history: artists should continue to pursue their critical mission - in fact they should take it very seriously, because scientific practice benefits from it. As most normative statements, this is not unproblematic. It can be argued, for example, that not all artists indiscriminately would agree on having this mission. Additionally, other actors apart from scientists might benefit from the critical role of art (the artists themselves, or the public, when these collaborations are aimed at "engagement"). My normative claim here focuses on what scientific objectivity has to gain from involving artists, perhaps more explicitly than in the past, in the practice of scientific 
visualisation. In this respect, I propose that the critical mission of art shares some of the features that characterize the role of philosophy of science: that of questioning and challenging assumptions and modes of working that would otherwise be taken for granted by scientific practitioners. ${ }^{15}$

My final case-study exemplifies this point. I draw on a 2009 work by the artist Martin John Callanan, entitled A Planetary Order (Global Terrestrial Cloud) (fig. 4).

\section{[Fig 4 here]}

Fig. 4. Martin John Callanan A Planetary Order (Global Terrestrial Cloud), 2009. Courtesy of the artist.

Callanan's artwork is a physical visualization of real-time "raw" scientific data. It captures at a glance one second of readings, taken on 2 February 2009 at exactly 0600 UTC, from all the six cloud-monitoring satellites overseen by NASA and the European Space Agency. The readings were transformed into a 3-D computer model, which was then 3-D printed at the Digital Manufacturing Centre at the UCL Bartlett Faculty of the Built Environment (Hamblyn and Callanan, 2009:67).

The layer of clouds that covers the globe's surface, and that only suggests the presence of continents underneath, creates a powerful perceptual shift: patterns of clouds that seem transient and mutable when viewed from earth form a coherent "planetary order" when seen from space. A Planetary Order gives a visible form to information that would have otherwise remained in the form of silent quantitative readings, whose self-evidence is generally accepted with no reservations by scientists. As a representation, the globe is not so much - or at least not exclusively - about the exact position of patterns of cloud over the Earth's surface. The piece seems instead to raise more fundamental questions about what count as supposedly "raw" data, and the various ways in which such data can be visualized.

Callanan's work was part of a broader project, carried out in 2009 in collaboration with the writer Richard Hamblyn. The project involved them

\footnotetext{
${ }^{15} \mathrm{I}$ am grateful to an anonymous referee for challenging this point in my discussion and allowing me to elaborate on it further (a clear case in which "critique" has benefits!).
} 
respectively as an artist and a writer in residence working in an interdisciplinary team of researchers at the UCL Environment Institute. Their collaboration aimed to use artistic visualization as a critique of the scientific rhetoric of "data". Their results converged in a book, aptly entitled Data Soliloquies (2009), which features

Callanan's A Planetary Order as one of its most iconic illustrations, and which draws on the visual narratives of climate change to underline more broadly "the extraordinary cultural fluidity of scientific data" (ibid.:13). The book has far reaching implications about the ways in which scientific data are communicated to the public, their often spectacular modes of representation, and the mechanisms of persuasion that are implicitly built in the display of large quantities of information. But a striking - albeit perhaps less obvious - aspect of the book is that it addresses, partly through Callanan's visual work, some important epistemological questions concerning the relation between data and their representation.

From the outset, Hamblyn and Callanan state that their aim is to "interrogate" data and bring to the fore the assumptions that far too often remain hidden behind their supposed self-evidence:

“Our title, 'Data Soliloquies'... reflects the ways in which scientific graphs and images often have powerful stories to tell, carrying much in the way of overt and implied narrative content; but also that these stories or narratives are rarely interrupted or interrogated. They are information monologues soliloquies - displayed more for their visual and rhetorical eloquence than for their complex (and usually hard-won) analytical content". (Hamblyn and Callanan, 2009:14)

Far from being "found objects", data are collected and constructed according to specific acts of judgment, which form intricate narratives and stories behind their visual immediacy and power. Hamblyn and Callanan's message is that the quantity of data available does not justify their self-evidence: data visualization involves first and foremost an act of discernment and choice, in which patterns are cautiously carved out of the inevitable statistical uncertainty that surrounds them.

Along with the shift from representation to presentation, which Daston and Galison identify as the latest frontier of correct depiction, the rhetoric of scientific objectivity has progressively turned to data and the statistical correlations between 
them as a guarantee of scientific reliability. ${ }^{16}$ This new appeal to objectivity hinges on quantity - a "data deluge" - without taking into account that its visual manifestations are themselves informed by judgment, discernment and choice. The task of the artist well exemplified by Hamblyn and Callanan's work - consists in giving a visible form to such an act of discernment, and this places artistic visualization once again in the uncomfortable position of serving as a challenge to the parameters that define scientific objectivity.

Artistic visualization as "critique" consists in bringing judgment and uncertainty to the fore, in questioning the self-evidence of scientific data and interrogating scientific visualization, rather than letting it flow as an uninterrupted and undisturbed soliloquy. Untied from the discipline of truth-to-nature and the restraints of mechanical objectivity, artists can now vocalize their objections to objectivity in ways that can be immediately heard by scientists, and that can explicitly feed into their practice.

The kind of attitude toward objectivity - or at least toward the supposed objectivity of scientific data - that these new controversies will open is still difficult to anticipate. But the fact that artistic practice is now looking at data - a foundational and still little questioned assumption in scientific practice - is a promise that artists' challenges to scientific modes of visualization will not spare the fundamentals.

\section{Historicising Representations: A plea for "Representative Practices"}

"All epistemology begins in fear - fear that the world is too labyrinthine to be threaded by reason; fear that the senses are too feeble and the intellect too frail; fear that memory fades, even between adjacent steps of a mathematical demonstration; fear that authority and convention blind; fear that God may keep secrets or demons deceive. Objectivity is a chapter in the history of intellectual fear, of errors anxiously anticipated and precautions taken". Daston and Galison (2007), p. 372

Representations have not been spared from the history of intellectual fear, which features objectivity as one of its central chapters. Reduced to formalisms and logical

\footnotetext{
${ }^{16}$ In a well known 2008 Wired Magazine article, for instance, Chris Anderson prophesized "the end of theories" as a result of the data deluge: "The new availability of huge amounts of data, along with the statistical tools to crunch these numbers, offers a whole new way of understanding the world. Correlation supersedes causation, and science can advance even without coherent models, unified theories, or really any mechanistic explanation at all". Anderson (2008), "The End of Theory", Wired
} 
relations, marginalized by philosophers as dispensable accessories of theories, representations have suffered the same fate as objectivity - perhaps because they constitute its most tangible materialization.

I began this chapter stating that my concerns about representation and visualization were mainly epistemological, and it is to those concerns that I want to return in my conclusions - even at the risk of adding a new chapter to the history of intellectual fear. In charting the story of how artists participated in the conversations and controversies surrounding accurate representations, I stressed that the history of scientific objectivity has constantly crossed paths with the history of artistic visualisation. Whether glaringly displayed on the pages of books, atlases and journals, or hidden in the background of eighteenth century engravings, artists' reactions to objectivity shaped its history, and with it the history of representation. The views I presented in the course of this chapter pose some challenges to current accounts of representation in philosophy of science. I want to offer two suggestions, which aim at providing a view of representations that reconciles epistemological and historical accounts, at the same time reconnecting them to the visual history of objectivity.

My first suggestion is that representations, even when conceptualized as epistemological relations, are inherently historical. This might seem a trivial point, but it is one rarely addressed by philosophers of science. The only way we have to make sense of the relation of representation - be it one of resemblance, denotation, idealization, abstraction or any of the various shades in between - is by looking at the processes that led to its construction.

The three case-studies that I presented in this chapter are a case in point. The interplay between background and foreground in Albinus' tables shows that his collaborator, Jan Wandelaar, was torn between idealisation - the criterion imposed by truth-to-nature - and particular representations. Wandelaar's epistemological dilemmas converged in tables IV and VIII, eventually shaping the distinctive representative character of the illustrations in Albinus' work. Stieglitz's conceptual approach to photography brought him beyond the realm of figurative depiction. Straight photography allowed him to move beyond a quest for a faithful correspondence between the image and its objects, and place the judgment of a trained 
"seer" right at the centre of what counts as a true picture. Lastly, Callanan's $A$

Planetary Order constructs representation as a translation of numerical data deriving from cloud readings into their 3-D, visual and tangible counterpart. Here figurative or conceptual representations are beside the point: what counts is the materialization of large datasets, their transposition into a material artefact that stands for the very artifactual nature of data. All three artists, despite belonging to very different historical periods, are concerned with the relation between their representations and the objects that such representations are meant to capture. Yet, what links these three very different forms of artistic experimentation is not the presence of a single, permanently fixed, representative relation: if anything, all these works suggest that representation consists of a plurality of relations. What brings these three artists together is their common quest for an alternative to current modes of scientific visualisation, of which their representations are a material incarnation. This quest is first and foremost an expression of how historical contingencies, arguments and controversies between artists and scientists ultimately feed into the relation of representation, and shape its final form.

Historicising representations ultimately amounts to bringing to the fore not just the reasons, but also the material and experimental practices involved in their construction. This leads me to a second and final suggestion: a plea to shift the focus of philosophical inquiry from "representation" to "representative practices", construed as the ways in which both artists and scientists devise useful and perspicuous ways of visualizing phenomena and experimenting upon them. ${ }^{17}$ Without denying the theoretical components that guide visualisation, the concept of representative practices captures at the same time the procedural and experimental aspects of representing, which far too often remain implicit in epistemological accounts. The case studies that I have presented in the course of this chapter show that artists and scientists' quest for "accurate" or "correct" ways of representing invokes questions about what counts as a representation in the first place, and yet the ways in which they arrive at such representations reflect a journey of visual discovery, which parallels their concrete experimentation upon phenomena. Thus construed, the shift to representative practices offers a useful means of reconciliation for two dominant

\footnotetext{
${ }^{17}$ I have sketched a formulation of representative practices, whose roots are in the Pragmatist account of representations proposed by Charles S. Peirce, in Ambrosio (forthcoming).
} 
strands in the literature on representations in philosophy of science. ${ }^{18}$ On the one hand, the concept of representation has been used by philosophers of science, especially within the analytic tradition, to investigate the relation between theory and the world. This approach suffers from the over-emphasis on theories and the bias toward the physical sciences that characterised most philosophy of science at least until the early 1980s. Its immediate drawback is that it tends to dismiss experimental practices as merely subservient to theories. Being concerned mainly with problems of meaning, reference and the metaphysics of relations, the proponents of analytical accounts focus exclusively on what constitutes a representation, and ultimately view it as a relation between a source (the vehicle of the representation) and a target (the object of the representation), which needs to be spelled out in terms of necessary and sufficient conditions (Suárez 2010:91ff).

The limits of such accounts have been partly recognised by philosophers of science. This has determined a recent shift in the literature on representation, which is in line with the contemporary tendency to integrate history and philosophy of science in a unified account. Rather than focusing on the nature of the relation of representation, recent accounts concentrate on uses and means as opposed to the constituents of representations. This approach draws on a more general turn towards practice in philosophy of science, inaugurated by Hacking's (1983) Representing and Intervening, which notoriously inverted the hierarchical relation between theory and experiment, placing the latter at the centre of philosophical investigation. This was paralleled by a renewed interest in the role of representations - and more precisely models - in scientific experimentation. ${ }^{19}$

Practice-based accounts focus on model building, rather than representation as a relation that needs to be spelled out analytically, as fundamental to scientific practice. Their starting assumption is that representations should be investigated in conjunction with the various uses of models and the particular contexts in which they are used. But despite its emphasis on the experimental contexts surrounding the use

\footnotetext{
${ }^{18}$ In drawing this distinction I follow Suárez (2010).

${ }^{19}$ The forerunners of this approach are Achinstein (1968), Black (1962) and Hesse (1963). Cartwright (1983) and Morrison and Morgan (1999) pioneered the shift toward practice-based approaches to models, whereas De Chadarevian and Hopwood (2004) have recently examined the historical context surrounding the production and use of models. More recent accounts include Suárez $(1999,2003)$ and useful overviews of this debate are in Frigg and Hunter (2010) and Suárez (2010). The turn to practice in philosophy of science has a sociological counterpart in the accounts of representation in practice presented in Lynch and Woolgar (1990).
} 
of models, there is a sense in which this new strand in philosophy of science had the effect of divorcing the theoretical implications of representations from their experimental uses and applications. The concern here is that the over-emphasis on use in the literature on models tends to reduce them to ready-made entities, whose importance lies exclusively in their practical applications. In this, the proponents of practice-based accounts share the same difficulties as their analytical predecessors: both seem to focus on the justification of the representative relation or of the ways in which we use representations, without explaining the process of discovery that is at stake in producing them. What I want to stress by appealing to a concept of "representative practices", instead, is that using representations is co-extensive with the process of constructing them.

Once again, the three case studies that I have presented in this chapter are a case in point. The stories behind Wandelaar's rhinoceros, Stieglitz's Steerage and Callanan's A Planetary Order are cases of visualisation construed as an experimental practice. They incorporate actions and physical processes - engraving, printing, lasermelting in 3-D - and serve practical purposes - observing, visualizing, experimenting with data, constructing persuasive arguments. But at the same time, all these practical actions also incorporate and convey a fundamental, theoretical quest for what counts as a representation in the first place. Thus construed, they should be interpreted as multi-layered arguments, rather than formalized relations or ready-made models fulfilling a single purpose.

Representative practices account for the key boundary areas in which art and science have complemented each other, and continue to do so in the age of computerization. They account for the process of experimental inquiry, both theoretical and practical, that has characterized the conversations and controversies between artists and scientists around the status and purposes of accurate representations, as well as around what representing amounts to in the first place. The history of objectivity tells us that these questions have shifted through time and, with them, so has the relation of representation. Truth-to-nature, mechanical reproducibility, expert judgment and the last frontier of representing large datasets: all the twists and turns that characterize the history of objectivity contribute to place a plurality of different relations at the basis of what counts as a representation. Such plurality is nourished and invigorated by the fact that, artists as much as scientists, do 
not divorce their theoretical questions about representations from their practical uses. It is in this sense that representative practices are part and parcel of the story of objectivity - and hopefully this account leaves only a note in the margins, rather than writing a new chapter, in the history of intellectual fear.

\section{Acknowledgments}

I am grateful to Annamaria Carusi, Aud Sissel Hoel, Timothy Webmoor, Steve Woolgar, and to an anonymous referee for their perceptive comments on all the preliminary drafts of this chapter. I owe a great deal to Lorraine Daston and Peter Galison for their kind encouragement and for engaging in several conversations which proved invaluable in shaping my argument. Niall Le Mage provided sharp editorial criticism on the final draft of this chapter, and I greatly benefited from his comments. The students on the course HPSC 3022: Science, Art, and Philosophy followed the development of this chapter since its earliest stages. Their enthusiasm, comments and questions contributed to give my story its present form.

\section{Bibliographical References}

Achinstein, P., 1968. Concepts of Science: A Philosophical Analysis, John Hopkins University Press, Baltimore.

Adato, P.M., 2001. American Masters - A. Stieglitz: The Eloquent Eye. New York: Winstar TV and Video.

Albinus, B.S., [1747] 1749. Tabulae Sceleti et Musculorum Corporis Humani (Leiden: J. \& H. Verbeck, 1747); translated as Tables of the Skeleton and Muscles of the Human Body (London: John and Paul Knapton).

Ambrosio, C., forthcoming. "Iconic Representation, Creativity and Discovery in Art and Science", in W. Gonzalez (ed.), Creativity and Complexity in Science, A Coruña: Netbiblo.

Anderson, C., 2008. “The End of Theory”, Wired Magazine, vol. issue 16.07 (23/06/2008) available at http://www.wired.com/science/discoveries/magazine/16-07/pb_theory . (Accessed 18/04/2012).

Bentley, J., 1970. "The Chemical Department of the Royal School of Mines: Its Origins and Development under A.W. Hofmann", Ambix, vol. 17: 15381. 
Bentley, J., 1972. "Hofmann's Return to Germany from the Royal College of Chemistry", in: Ambix, vol. 19: 197-203.

Black, M., 1962. Models and Metaphors, Cornell University Press, Ithaca and New York, 1962.

Cartwright, N., 1983. How the Laws of Physics Lie, Oxford University Press, Oxford, 1983.

Castel, B., and Sismondo, S., 2008. The Art of Science. Toronto: University of Toronto Press.

Choulant, L., 1962. History and Bibliography of Anatomic Illustration. Trans. and annotated by Mortimer Frank. (New York: Hafner), pp. 276-283.

Clarke, T.H., 1974. "The Iconography of the Rhinoceros. Part II: The Leyden Rhinoceros". The Connoisseur, (February issue), pp. 113-122.

Collins, H. and Pinch, T., 1993. The Golem: What Everyone Should Know About Science. Cambridge: Cambridge University Press.

Daston, L., 2008. “On Scientific Observation”, ISIS 99, no. 1:97-110.

Daston, L. and Galison, P. 2007, Objectivity. New York: Zone Books.

De Chadarevian, S. and Hopwood, N. (eds.), 2004. Models: The Third Dimension of Science. Stanford: Stanford University Press

De Zayas, M., 1910. "Photo Secession Notes", Camera Works no. 30, p. 47.

Didi-Hubermann, Georges, 1986. "Photography - Scientific and Pseudo-Scientific", in: A History of Photography: Social and Cultural Perspectives, ed. by Jean-Claude Lamagny and André Rouillé. Cambridge: Cambridge University Press, pp.71-76.

Elkins, J., 1986. "Two Conceptions of the Human Form: Bernhard Siegfried Albinus and Andreas Vesalius", Artibus et Historiae, vol. 7, no. 14, pp. 91-106.

Eversole, T., 2005. “Alfred Stieglitz's Camera Work, and the Early Cultivation of American Modernism”, Journal of American Studies of Turkey, vol. 22: $5-18$.

Ferguson, J. P., 1989. "The skeleton and the rhinoceros". Proceedings of the Royal College of Physicians of Edinburgh, vol. 19(2): 231-2.

Francisco, J. and McCauley, E.A. (2012). The Steerage and Alfred Stieglitz. Berkeley, Los Angeles, London: University of California Press. 
Frigg, R. and Hunter, M. (eds.), 2010. Beyond Mimesis and Convention: Representation in Art and Science, Springer, Dordrecht.

Hamblyn, R. and Callanan, M. J., 2009. Data Soliloquies. London: The UCL Environment Institute.

Hanson, C. A., 2010. "Representing the Rhino: The Royal Society between Art and Science in the Eighteenth Century", Journal of Eighteenth-Century Studies vol. 33 no. 4, pp. 545-566.

Hildebrand, R., 2005. "Attic Perfection in Anatomy: Bernhard Siegfried Albinus (1697-1770) and Samuel Thomas Soemmering (1755-1830)". Annals of Anatomy, vol. 187, pp. 555-573.

Holmes, F. L., 1989. "The Complementarity of Teaching and Research in Liebig's Laboratory", OSIRIS ( $2^{\text {nd }}$ series), vol. 5: 121-164.

Huisman, T., 1992. "Squares and Diopters: the Drawing System of a Famous Anatomical Atlas." Tractrix, vol.4: 1-11.

Kiefer, G., 1991. Alfred Stieglitz: Scientist, Photographer and Avatar of Modernism, 1880-1913. New York and London: Garland Publishing Inc.

Jackson, C. M., 2009. Analysis and Synthesis in Nineteenth Century Chemistry. PhD Thesis, University of London.

Latour, B., 1987. Science in Action. Cambridge, Mass.: Harvard University Press.

Lowe, S., 2002. Alfred Stieglitz. A Memoir/Biography. Boston: Museum of Fine Art Publication ( $2^{\text {nd }}$ edition).

Lynch, M. and Woolgar, S., 1990. Representation in Scientific Practice. Cambridge, Mass.: The MIT Press.

Meinel, C., 1992. "August Wilhelm Hofmann - "Reigning Chemist-in-Chief”, Angewandte Chemie, vol. 31, no. 10, pp. 1265-1398.

Meinel, C., 2004. "Molecules and Croquet Balls", in: S. De Chadarevian and N. Hopwood (eds.) Models: the Third Dimension of Science Stanford: Stanford University Press, 2004, pp. 242-275.

Norman, D. (ed.), 1942-43. “Alfred Stieglitz; Four Happenings”, Twice a Year vols. 8-11:105-137.

Norman, D., 1973. Alfred Stieglitz: An American Seer, New York: Random House. 
Punt, H. (1983). Bernard Siegfried Albinus (1697-1770), On 'Human Nature'.

Anatomical and Physiological Ideas in Eighteenth Century Leyden. Amsterdam: B.M. Isräel.

Rookmaaker, L.C., 1976. "An Early Engraving of the Black Rhinoceros (Diceros bicornis (L.)) Made by Jan Wandelaar", Journal of the Linnean Society, vol. 8, pp.87-90.

Rookmaaker, L.C., 2005. "Review of the European Perception of the African

Rhinoceros", Journal of the Zoological Society of London, vol. 265, pp. 365-376.

Schiebinger, L., 1986. "Skeletons in the Closet: The First Illustration of the Female Skeleton in Eighteenth-Century Anatomy". Representations, no. 14, pp. 42-82.

Steichen, E., 1903. "Ye Fakes", Camera Works, vol. 1. Reprinted in Alfred Stieglitz. Camera Work: The Complete Illustrations 1903-1917, ed. by S. Philippi and U. Kyeseyer, with an introduction by P. Roberts. Cologne: Taschen, 1997.

Suárez, M., 1999. "Theories, Models, and Representations" in L. Magnani, N.J. Nersessian and P. Thagard (eds.), Model-Based Reasoning in Scientific Discovery, Kluwer Academic Press, New York.

Suárez, M., 2003. "Scientific Representation: Against Similarity and Isomorphism", International Studies in the Philosophy of Science, vol. 17 no. 3, pp. 225-244.

Suárez, M., 2004. "An Inferential conception of Scientific Representation", Philosophy of Science, no. 71, pp. 767-779.

Suárez, M. (2010). “Scientific Representation”, Philosophy Compass vol. 5, no. 1, pp. 91-101.

Wilder, K., 2009. Photography and Science. London: Exposures. 